\title{
Intracranial reinforcement: Performance decrements as a function of stimulus parameters
}

THOMAS W. WESTCOTT, LARRY D REID, and RONALD E. WASDEN, Bradley University, Peoria, III. 61606

Rats, on ad lib food and water schedules, nan a maze for intracranial stimulation with an independent variable of different intensities or durations of the reinforcer. The performance decrement of the first trial of a set of massed trials, sometimes seen with intracranial reinforcement, was found to be a function of the values of the brain stimulation with some rats.

It has been concluded that $S$ s trained with intracranial reinforcement show a decrement in performance when the trials are spaced (e.g., Gallistel, 1964; Morgan, 1965; Deutsch \& Deutsch, 1966; Hilgard \& Bower, 1966; Kendler, 1968). Such a conclusion leads one to expect that (a) maze running times of the first trial would be inordinately long, and often Ss would have to be "primed" to initiate responding,(b) training would be difficult on intermittent schedules of reinforcement, and (c) extinction would be rapid and time-dependent rather than response-dependent. There is evidence to support each of these expectations (Deutsch \& Deutsch, 1967). An assumption of Deutsch has tied these conclusions and data into a common framework: "each brain stimulus excites a drive pathway, and that in the removal of such a stimulus such excitation decays [Deutsch \& Deutsch, 1967, p. 122]."For Deutsch, performance for intracranial stimulation (ICS) can be maintained only by massed ICS trials or by excitation of "drive pathways" by deviations from homeostasis. Moreover, the effects from these conditions can add to maintain performance for ICS.

Evidence contradictory to Deutsch's ideas of intracranial reinforcement is plentiful: (a) discrete trial performance decrements may not be present (Wasden, Reid, \& Porter, 1965; Wasden, 1966; Scott, 1967; Wasden \& Reid, 1968), nor do all investigators find it necessary to start their Ss performing with "free trains" of ICS (Kornblith \& Olds, 1968), (b) training for ICS on lengthy temporal schedules of reinforcement has been accomplished (Pliskoff, Wright, \& Hawkins, 1965), and (c) extinction may not be rapid nor time-dependent, especially when the contingencies of reinforcement are similar to the circumstances of extinction with conven- tional reinforcers (Gibson, Reid, Sakai, \& Porter, 1965; Reid, 1967; Panksepp \& Trowill, 1967).

Each of these supposedly discrepant results has been "explained" on the premise that some "natural drive" is interacting with the ICS to maintain Ss' performance for ICS (Duetsch \& Deutsch, 1966; Deutsch \& DiCara, 1967). As with another controversy (is drive reduction necessary for learning?), it is always possible to postulate some drive as being present [and potentially reduced (Brown, 1953)], so it is convenient to use this explanation for data that are apparently contradictory. If it can be demonstrated that discrete trial performance decrements will vary with changes in stimulus parameters and not with the condition of the $S$, then, at least, the explanation of the decrement in terms of some potential drive being present is not the only possible explanation. In other words, changes of first-trial performance would be related to other variables and unrelated, except when specifically varied, to changes from homeostasis. We believe the following data provide such a demonstration.

\section{METHOD}

Subjects were six adult male albino rats, fixed, in standard ways, with chronically indwelling bipolar electrodes so that the lateral hypothalamus could be stimulated. Following the experiment, sites of stimulation of four Ss were verified by direct inspection of frozen sections of the brain (sites were at or near the medial forebrain bundle, lateral to the fornix, medial to crus cerebri, at the plane of the ventral medial $n$. or just posterior to it).

All testing was in a $\mathbf{C}$-shaped runway, $305 \mathrm{~cm}$ long, $12 \mathrm{~cm}$ wide, with walls $29 \mathrm{~cm}$ high. The startbox had a sliding gate and the goalbox a Scientific Prototype rat lever. A time-meter started when the startbox was opened and stopped when $\mathrm{S}$ pressed the goalbox lever.

In the goalbox, each $S$ pressed for ICS (40 to $60 \mu \mathrm{A}$ of 60 cycle ac, with ad lib durations up to $.5 \mathrm{sec}$ ) during their first opportunity at rates greater than 10 presses a minute. After press rates had become somewhat stable at these ICS values, Ss were trained to run the maze, five trials a day, beginning the same time each day, with $1 \mathrm{~min}$ between trials. If a $S$ failed to press within $200 \mathrm{sec}$ after the startbox opened, it was placed in the goalbox and allowed the standard 25 presses. Food and water were always available in Ss' home cages.

When conditions remain constant, the presence or absence of an overnight performance decrement and, if present, the magnitude of the decrement, does not change after the first few days of testing (Wasden, 1966). Therefore, Ss were tested at different values of ICS for at least 7 days and the last 5 days' performance was taken as the index of Ss' responsiveness. After testing with the value of ICS used to train Ss, the intensity or duration of ICS was increased (for intensity in $20 \mu \mathrm{A}$ steps) and testing continued as before. Following tests with the highest intensity (.5-sec ad lib durations), three Ss were tested similarly at the highest intensity but with ICS-durations that lasted for $.5 \mathrm{sec}$ regardless of the duration of lever depression. One $S$ was tested further with a fixed duration of $.75 \mathrm{sec}$. With some Ss, testing continued until the magnitude of ICS was of lesion-producing values, and a few were retested at the lower intensities.

The data of each $S$ (running times of the five trials of the last 5 days of the first tests with each stimulus parameter) were summarized using the two-factor design with repeated measures on one factor described by Winer (1962, p. 302) with the exception that each day's data were treated as if it were from separate Ss.

\section{RESULTS}

Subject 335 showed no overnight or between-trials decrement in performance at any of the values tested (Fig. d). The range of all of the first daily trials $(\mathrm{N}=50)$ was $4-10 \mathrm{sec}$ (with only one trial of $10 \mathrm{sec}$ and one of $9 \mathrm{sec}$ ). This $S$ ran nearly all trials $(N=250)$, no matter what the stimulus

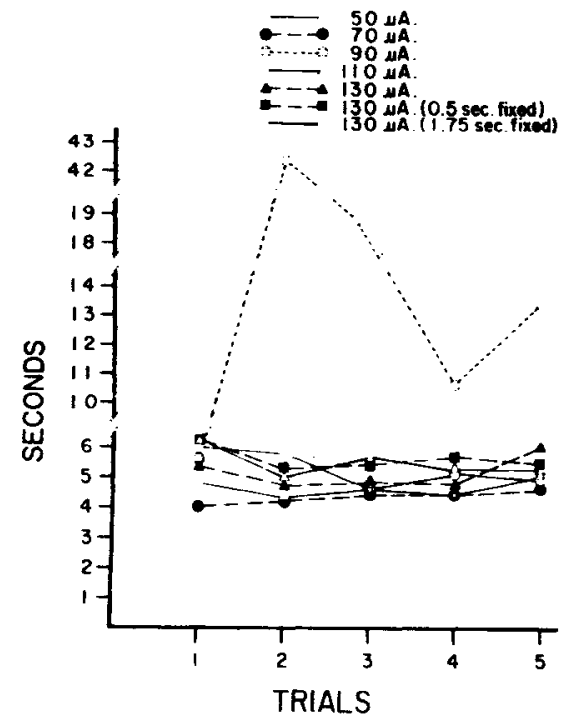

Fig. 1. Mean running times for each of five daily trials at six intensities taken from 5 days of tests with each intensity. 


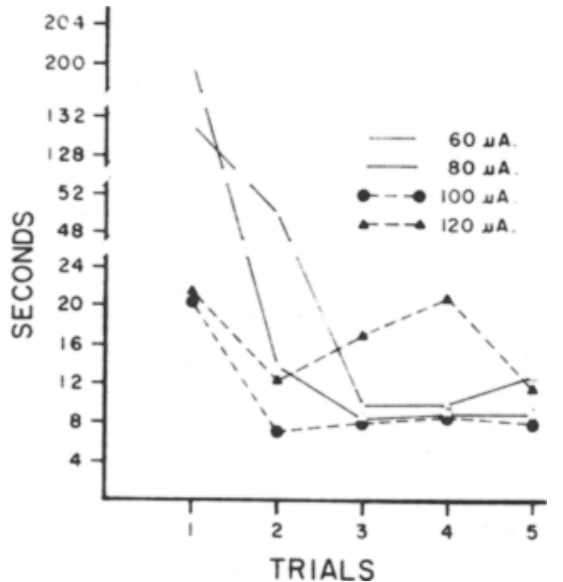

Fig. 2. Mean running times for each of five daily trials at four intensities taken from 5 days of tests with each intensity.

values, in less than $10 \mathrm{sec}$, with the exception of eight trials at $90 \mu \mathrm{A}$ that were inordinately long.

Similar behavior was exhibited by $S 383$ that was tested at the same values as $\mathrm{S} 335$, except for the $.75-\mathrm{sec}$ fixed duration. The mean first-trial running time was $7 \mathrm{sec}$ $(\mathrm{N}=42)$ with a range from $6-9 \mathrm{sec}$. All but three of the total trials $(N=210)$ were run in less than $10 \mathrm{sec}$. Its performance, like that of S 335, was similar to $\mathrm{Ss}$ running for conventional reinforcers.

Subject 334 (Fig. 2) had a conspicuous overnight performance decrement at 60 and $80 \mu \mathrm{A}$ and a much smaller "decrement" at the higher intensities (there was no overlap in distribution of the first-trial running times of 60 and $80 \mu \mathrm{A}$ and those of 100 and $120 \mu \mathrm{A})$. The relationship between intensity and trials is summarized by the interaction term of the $\operatorname{ANOV}(\mathrm{F}=16, \mathrm{df}=12 / 64)$. The slow first trials at the lower intensities cannot be attributed to a potentially lower incentive, since Trials 3,4 , and 5 were run faster for $60 \mu \mathrm{A}$ than for $120 \mu \mathrm{A}$.

Subject 169 was tested at three intensities $(60,80$, and $100 \mu \mathrm{A})$. Running times with $60 \mu \mathrm{A}$ were slow on Trials 1,2 , and 3 (means $=138,200$, and $53 \mathrm{sec}$, respectively) and faster on Trials 4 and 5 ( 10 and $9 \mathrm{sec})$. When $100 \mu \mathrm{A}$ was used, the mean running times for the five trials were $94,23,9,16$, and 10 sec. As with S 334, higher intensities reduced the magnitude of the first trial decrement (Intensity by Trial interaction: $F=15, \mathrm{df}=8 / 48$ ).

Subject 337 (Fig. 3) exhibited a conspicuous first-trial performance decrement at 90 and $110 \mu \mathrm{A}$ and a small, insignificant "decrement" at 50 and $70 \mu \mathrm{A}$ (the difference being summarized by a Student $t$ of $1.88, \mathrm{df}=18$ ). The Trials by Intensity interaction term yielded an $F=2$, $\mathrm{df}=12 / 64$.
Subject 54 was tested at .5 -sec ad lib and $.5-\sec$ fixed duration with an intensity of $40 \mu \mathrm{A}$. Mean running times for the ad lib durations Trials 1 to 5 were $16,22,18,37$, and $21 \mathrm{sec}$ and for the fixed durations were $47,29,30,24$, and $14 \mathrm{sec}$. The Trials by Duration term of the ANOV yielded an $F=2.7$, df $=4 / 32$. As with changes in intensity, the most dramatic effect from changes in duration were exhibited on the first of the daily trials.

\section{DISCUSSION}

Even though the limits of our tests were narrow, the variety of results is remarkable: The running times for the first trial of a day increased, decreased, or were never conspicuously long as a function of increasing the value of ICS. These data certainly suggest caution in theorizing from a limited sample of sites and values of ICS (a situation that 14 years of rather intensive research has failed to overcome).

These data are not compatible with Deutsch's drive-decay hypothesis. To account for the two Ss that never ran slowly for ICS, even after $24 \mathrm{~h}$ with no brain stimulation, it is necessary to postulate some drive being present that never waned with up to $\mathbf{5 0}$ days of testing. For the other $\mathrm{Ss}$, it is necessary to postulate that the condition of the Ss changed just as the ICS values were changed. Since all Ss lived under the same laboratory conditions throughout testing, and since they were not deprived of food or water, it is unlikely that waxing and waning of drive was correlated with running times for ICS.

These data, with our other data, allow the following summary statements about performance decrements with ICS: (a) Some Ss show no decrement. (b) Some $S s$ show marked decrement on spaced trials at only some values of ICS. (c) When stimulus parameters are manipulated the greatest effect is on the first trial of a set of massed

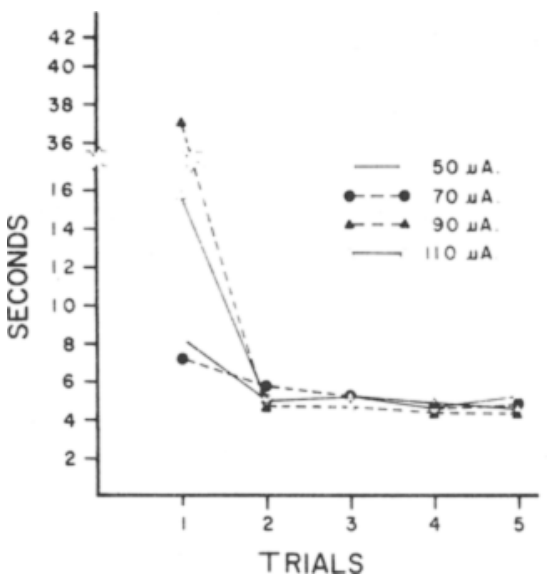

Fig. 3. Mean running times for each of five daily trials at four intensities taken from 5 days of tests with each intensity. trials and less effect on subsequent trials. And (d) a number of manipulations can alleviate the decrement, including injections of sodium amytal (a fear-reducing drug), the imposition of less than reinforcing intensity of ICS, and having S first run the maze but getting no ICS.

We cautiously suggest that the first application of ICS can be, in some way, noxious compared to subsequent ICS. This noxiousness will be more likely the more elements outside the medial forebrain bundle that are activated (Wasden et al, 1965). Therefore this discomfort is a complex function of site and magnitude of stimulation. Perhaps, the stimulation is noxious with Ss showing a performance decrement because it produces too great a difference in autonomic nervous system activity between period of no stimulation and immediately after stimulation. As activity builds with successive bursts of ICS the additional arousal is not so discrepant as to be noxious. It is analogous to a swimmer standing at the edge of a cold pool of water on a hot day; it is the first contact that is dreaded, not subsequent contacts.

Regardless of other implications of these data, it is evident that variation in stimulus parameters is a variable that contributes significantly to differences in performance on spaced trials with ICS and should be considered when studying ICS as a reinforcer.

\section{REFERENCES}

BROWN, J. S. Comments on Professor Harlow's paper. Nebraska symposium on current theory and research. Lincoln: University of Nebraska Press, 1953.

DEUTSCH, J. A., \& DEUTSCH, D. Physiological psychology. Homewood, Ill.: Dorsey, 1966.

DEUTSCH, J. A., \& DiCARA, L. Hunger and extinction in intracranial self-stimulation. Journal of Comparative \& Physiological Psychology, 1967, 63, 344-347.

GALLISTEL, C. R. Electrical self-stimulation and its theoretical implications. Psychological Bulletin, 1964, 61, 23-34.

GIBSON, W. E., REID, L. D., SAKAI, M., \& PORTER, P. B. Intracranial reinforcement compared with sugar-water reinforcement. Science, 1965, 148, 1357-1359.

HILGARD, E. R., \& BOWER, G. H. Theories of learning. (3rd ed.) New York: AppletonCentury-Crofts, 1966.

KENDLER, H. H. Basic psychology. New York: Apple ton-Century-Crofts, 1968.

KORNBLITH, C., \& OLDS, J. T-maze learning with one trial per day using brain stimulation reinforcement. Journal of Comparative \& Physiological Psychology, 1968, 66, 488-491.

MORGAN, C. T. Physiological psychology. New York: McGraw-Hill, 1965.

PANKSEPP, J., \& TROWILL, J. A. Intraoral self injection: II. The simulation of self-stimulation phenomena with a conventional reward. Psychonomic Science, 1967,9, 407-408.

PLISKOFF, S. S., WRIGHT, J. E., \& HAWKINS, T. D. Brain stimulation as a reinforcer: Intermittent schedules. Journal of the Experimental Analysis of Behavior, 1965, 8, 75-88.

REID, L. D. Reinforcement from direct stimulation of the brain. Unpublished doctoral dissertation, University of Utah, 1967. 
SCOTT, J. W. Brain stimulation reinforcement with distributed practice: Effects of electrode intensity. Joumal of Comparative \& Physiological Psy chology, 1967, 63, 175-183. Overnight performance decrement with intracranial reinforcement. Psychological Reports, $1965,16,653-658$.

WASDEN, R. E. Intracranial reinforcement and lished doctoral dissertation, University of Utah, 1966. locus, previous experience, and stimulus

WASDEN, R. E., REID, L. D., \& PORTER, P. B. the overnight performance decrement. Unpub-
WASDEN, R. E., \& REID, L. D. Intracranial stimulation: Performance decrements and a fear-reducing drug. Psychonomic Science, 1968, 12,117-118.

WINER, B. J.Statistical principles in experimental design. New York: McGraw-Hill, 1962.

NOTE

1. This study was supported, in part, by fund from the Faculty Research Committee, Bradley University.

\section{Effects of concurrent exposure to different food and sucrose re- wards in differential conditioning}

JAMES R. ISON and DAVID H. GLASS, University of Rochester, Rochester, N. Y. 14627

In one experiment two control groups were run to either an eight-pellet reward or a one-pellet reward and a discrimination group was run to eight pellets on one stimulus and one pellet on a second stimulus. The discrimination group ran slower to the one-pellet stimulus than did the low-reward control group, indicating the presence of a concurrent depression effect. In the second experiment the same design was used but a high sucrose reward was contrasted with a low sucrose reward. The rate of differentiation was retarded in the sucrose experiment compared to the food pellet experiment and no depression effect was observed, although the functional difference between the sucrose rewards was greater than between the food pellet rewards. These data indicate that the difference between sucrose and food pellet rewards obtained in sequential shift experiments is also obtained in concurrent shift experiments.

Two primary effects are obtained in the usual sequential reward shift experiment in which rats receive a succession of trials with high food reward followed by a succession of trials with a low food reward. Approach behavior, first, rapidly declines, and, second, drops below the level achieved by a nonshift control group which receives low reward throughout. This latter phenomenon defines the sequential "depression effect."

A similar depression effect is obtained in the concurrent reward shift experiment in which rats receive intermixed exposure to the two rewards. In such experiments a high reward is made consequent to one stimulus-response combination and a low with different sucrose rewards, first, should tion (analogous to the slow change in paradigm) and, second, should not provide a concurrent depression effect (analogous to the failure to produce a sequential depression effect). The experiments reported here were performed initially for different purposes. However, they were alike in basic procedural details, and the data are relevant to this point.

\section{SUBJECTS}

Male hooded rats $(\mathrm{N}=70)$, approximately $300 \mathrm{~g}$ in weight were obtained from the Blue Spruce Farms, Altamont, New York.

\section{APPARATUS}

A straight alley ( $83 \times 4 \times 5 \frac{1}{4}$ in.) was painted flat black and covered by frosted Plexiglas. Two side doors, one 12 in. and the other $15^{1 / 2}$ in. from the ends of the alley, served, respectively, as start- and goalbox doors. The runway was placed within a large sound-attenuating hull with a Plexiglas slot in the roof. A 5 -ft fluorescent bulb placed immediately over this slot was illuminated on designated trials by the opening of the start door. The discriminanda were the presence (L) or the absence (D) of this illumination. A $1 / 2$-in. hole in the side of the goalbox permitted access to a drinking tube which contained the appropriate sucrose solution. The drinking tube was controlled by a drinkometer circuit which retracted the tube at the designated lick count. Photocells placed on the start door, and 6 in., 54 in., and $62 \mathrm{in.} \mathrm{down} \mathrm{the} \mathrm{alley,} \mathrm{attached} \mathrm{to}$ Hunter Klockcounters, permitted measurement of start, run, goal, and total times. In the food-reward experiment the aperture in the side of the goalbox was closed and the reward was presented in a glass coaster behind a baffle at the far end of the goalbox. PROCEDURE

One week before training Ss were placed on a $23-\mathrm{h}$ food deprivation schedule (water ad lib) and were handled for $5 \mathrm{~min}$ each day. Within each experiment the rats were randomly assigned to three groups. One lead to relatively slow response differentiaperformance obtained in the sequential
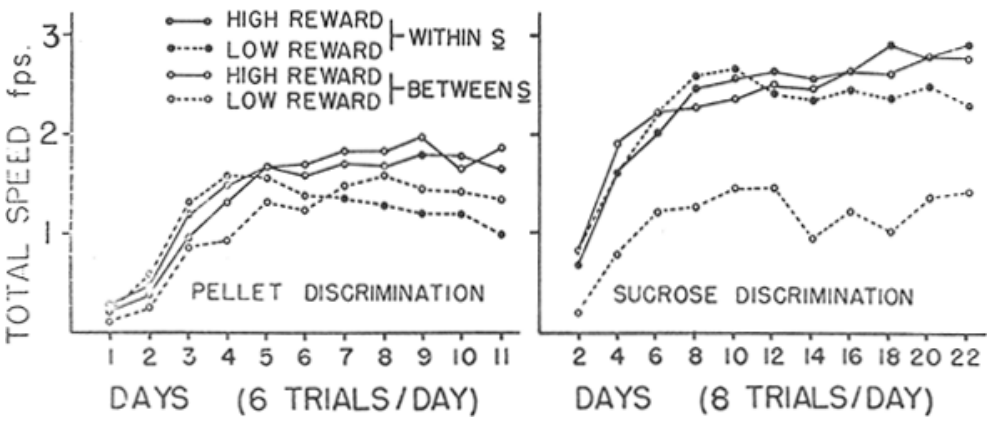

Fig. 1. Mean total response speed for groups receiving only a high reward or a low reward to both stimuli and differential groups receiving the high reward on one stimulus and the low reward on a second stimulus. 